\title{
THE ROLE PLAYED BY PMOS IN THE TRANSFER OF KNOWLEDGE BETWEEN PROJECTS: A CONCEPTUAL FRAMEWORK
}

\author{
B. Tshuma ${ }^{1 * \#}$, H. Steyn ${ }^{1} \&$ C. van Waveren ${ }^{1}$
}

\section{ARTICLE INFO}

\section{Article details}

Submitted by authors $\quad 12$ Apr 2018 Accepted for publication 31 Jul 2018 Available online $\quad 31$ Aug 2018

\section{Contact details}

* Corresponding author tshucksly@gmail.com

Author affiliations

1 Department of Engineering and Technology Management, University of Pretoria, South Africa

\# $\quad$ Author was enrolled for a PhD in the Department of Engineering and Technology Management, University of Pretoria, South Africa

DOI

http://dx.doi.org/10.7166/29-2-1966

\section{ABSTRACT}

Projects are unique, temporary structures that produce unique knowledge. For organisations to gain competitive advantage, this knowledge needs to be transferred effectively between projects. Knowledge transfer across projects is thus an important and decisive competitive factor. However, project teams typically focus on short-term project goals, and often fail to regard capturing and transferring project knowledge between projects as important for the long-term benefit of the organisation. This theoretical study argues that Project Management Offices (PMOs) play an important role by supporting and facilitating the flow of knowledge between projects. A conceptual framework depicting the role of PMOs in the transfer of knowledge between projects is presented here, while empirical results will be reported on in a sequel to this paper.

\section{OPSOMMING}

Projekte is unieke, tydelike strukture wat unieke kennis lewer. Vir organisasies om 'n mededingende voordeel te behaal, moet hierdie kennis effektief oorgedra word tussen projekte. Kennisoordrag tussen projekte is dus ' $n$ belangrike en beslissende mededingende faktor. Projekspanne fokus egter tipies op korttermyn projekdoelwitte en slaag dikwels nie daarin om die vasvang en oordra van projekkennis tussen projekte as belangrik vir langtermynvoordele vir die organisasie te beskou nie. Hierdie teoretiese studie voer aan dat Projekbestuurskantore (PMOs) 'n baie belangrike rol speel deur die vloei van kennis tussen projekte te ondersteun en te fasiliteer, en stel 'n konseptuele raamwerk voor wat die rol van PMOs in die oordrag van kennis tussen projekte uitbeeld. Empiriese resultate sal in 'n opvolgartikel gerapporteer word.

\section{INTRODUCTION}

Knowledge transfer is the process through which one organisational unit is affected by the experience of another [1]. The management of knowledge transfer between temporary organisations (projects) is an increasingly important and even decisive competitive factor [2]. Toledo, Chiotti and Galli [3] state that organisations realise the importance of exploiting and developing knowledge within their organisations as a tool to increase their competitive advantage. Although many organisations find knowledge transfer very challenging, its success is critical to the success of the project portfolio [4]. This is because projects produce high volumes of knowledge. However, the unique and temporary nature of projects [5], [6] makes the management of knowledge transfer between them a significant nightmare for most project organisations [3]. Moreover, the temporary nature of projects - in which project team members focus on the short-term goals of the project, and often fail to see the capturing and transferring of project knowledge across projects as a priority, or as important for long-term benefits to the organisation [7] - makes knowledge capturing and transferring between projects a major challenge. 
However, Project Management Offices (PMOs) are thought to be catalysts that moderate (support) and mediate (facilitate, coordinate, and control) the transfer of knowledge between various projects [8]. This paper argues that, without a formalised structure like a PMO that focuses on both the short-term (project efficiency, impact on the project team, and impact on customer [9]) and long-term (alignment of projects and organisation strategy, preparing for the future and business success [10]) objectives of project portfolio success, effective and efficient project knowledge transfer could be very difficult to achieve. Although PMOs fullfil this important integrative role, no study that models the role played by PMOs in the transfer of knowledge between projects could be found. This theoretical study (based on a literature survey) therefore explores the role played by PMOs in supporting and facilitating the flow of knowledge between projects, and presents a conceptual framework that depicts the role of PMOs in the transfer of knowledge between projects.

PMOs mediate and moderate the transfer of knowledge between projects by embedding accumulated knowledge from past project experiences into project management routines that are used across multiple projects in the organisation [11]. In as much as the ability to consolidate learning from previous projects is crucial, the problem in the practical environment is that project employees usually do not get the time to share, evaluate, align, and capture the knowledge before moving to the next project [12]. Their goals are project-specific and short-term in nature. PMOs mitigate the risk of losing project knowledge due to time constraints on the project teams. The overarching research question, therefore, is: "To what extent do PMOs moderate (support) and mediate (facilitate) the flow of knowledge between projects?"

\subsection{Project Management Offices}

The need to coordinate large, complex contracts that included many projects for a single large customer in the defence industry led to the birth of PMOs in the middle of the twentieth century [13]. Unger, Gemünden and Aubry [8] attributed the formation of PMOs to the challenges faced by project-based organisations (PBOs) in managing multiple projects as an integrated unit. Since then, the establishment of PMOs has increased steadily - an indication that many organisations believe that PMOs are central to attaining their goals and objectives [14]-[16]. A PMO (also known as a project support office [17], project office [18], project management centre of excellence [19], directorate of project management [20], [21] or project management unit) is an organisational focus-point for the project management function, and provides support, methods, procedures, systems, and policy for project management across the organisation [22]; it is an organisational entity with full-time personnel to provide and support managerial, administrative, training, consulting, and technical services for PBOs [19]; and it is a unit or department whose objectives are to assist and support project managers and facilitate good project management practices in a project organisation [23]. Their main functions and responsibilities include improving project management competency, implementing project management standards and methodologies, and providing support to project management teams and to portfolio management [23].

\subsection{Objective of the study}

The literature reviewed indicates a need for a model that simulates the facilitation and supporting role of PMOs in the transfer of knowledge between projects. This study thus seeks to fill this need by developing a conceptual framework that simulates the moderation (support) and mediation (facilitation) roles of PMOs in inter-project knowledge transfer. This would close the gap between short- and long-term project objectives in PBOs, since most project team members focus on the short-term goals of the project, and often fail to regard capturing and transferring of project knowledge across projects as a priority, or as bringing important long-term benefits to the organisation [7]. We believe that such a model could assist PBOs to maximise efficiency and thus gain a competitive advantage. This paper begins with a brief overview of a knowledge transfer framework, looks at an organisational model and uses it to develop a knowledge transfer framework that is spearheaded by the PMO, and lays out the context variables (characteristics of projects). Characteristics of knowledge generated and sent (independent variables), characteristics of knowledge received and used (dependent variables), and knowledge transfer elements (knowledge transfer infrastructure and processes) are discussed in sections three, four, and five respectively. In section six, the moderating and mediating roles of the PMO on the relationship between knowledge generated and sent and knowledge received and used are modelled. Three main propositions are then put forward, and a conceptual model is presented to help better understand the role of PMOs 
in the transfer of knowledge across projects. Finally, conclusions are drawn, and an avenue for further research is discussed.

\section{KNOWLEDGE TRANSFER FRAMEWORK}

Osterloh and Grand [24] defined a framework as an instrument to structure convoluted problems and a starting point for the development of alternatives for action. A knowledge transfer framework thus seeks to systemically structure knowledge transfer elements, their relationships, and the principles of how these elements interact [24]. Knowledge transfer infrastructure (people, tools, routines, and systems) and knowledge transfer processes (create, store, share, and use) are the main elements that drive knowledge transfer in organisations [4], [24]-[26]. The general objective of knowledge transfer management is to improve the systematic interaction of knowledge transfer infrastructure and processes within an organisation [24]; and PMOs play a significant role in the management, interaction, and integration of these elements and in ensuring the success of knowledge transfer across projects.

\subsection{Organisational model}

In a typical PBO with a PMO to direct projects, the PMO moderates and/or mediates the flow of knowledge between projects, as shown in Figure 1. Either (a) knowledge is transferred from one or more projects to the other(s) and the PMO moderates the process, or (b) project knowledge is transferred from project(s) to the PMO and then from the PMO to other projects. In the latter, the PMO acts like a knowledge repository; it manages the knowledge by determining what knowledge to transfer and when and how to transfer it to the respective project(s), depending on the needs of the receiving project(s).

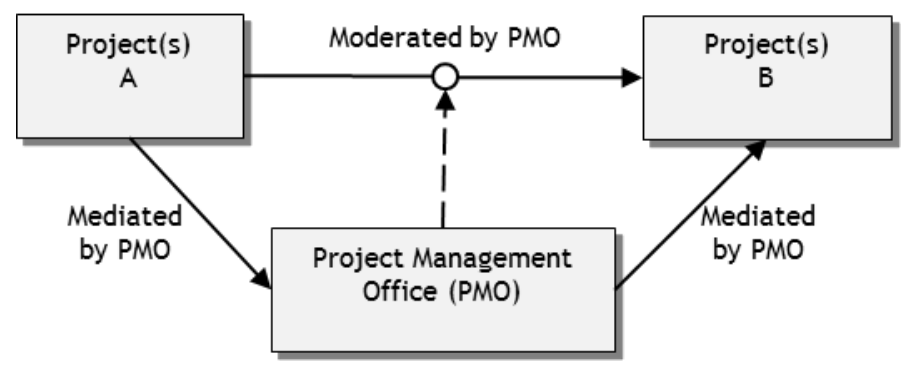

Figure 1: Project knowledge flow in a typical PBO with a PMO

\subsection{PMO's role in the knowledge transfer framework}

Similary to the PBO with a PMO (Figure 1), PMOs play a coordination (resource allocation across projects), controlling (establishing and maintaining a sound knowledge base) and supporting (cultivating project management standards, improving knowledge transfer between projects and communication) role in the knowledge transfer framework [8]. They are responsible for the management of the whole knowledge transfer framework, which in turn improves the transfer of knowledge between projects. Based on the flow of knowledge in a typical PBO with a PMO (Figure 1), a knowledge transfer framework that is driven by the PMO has been established. Knowledge transfer revolves around the management of knowledge tranfer infrastructure and processes [24]. To articulate the role of PMOs in the transfer of knowledge across projects, we established the characteristics of the knowledge generated and sent, the characteristics of the knowledge received and used, and the characteristics of the support and faclitation provided by the PMO, as shown in Figure 2. These characteristics are discussed in detail in sections three to five. 


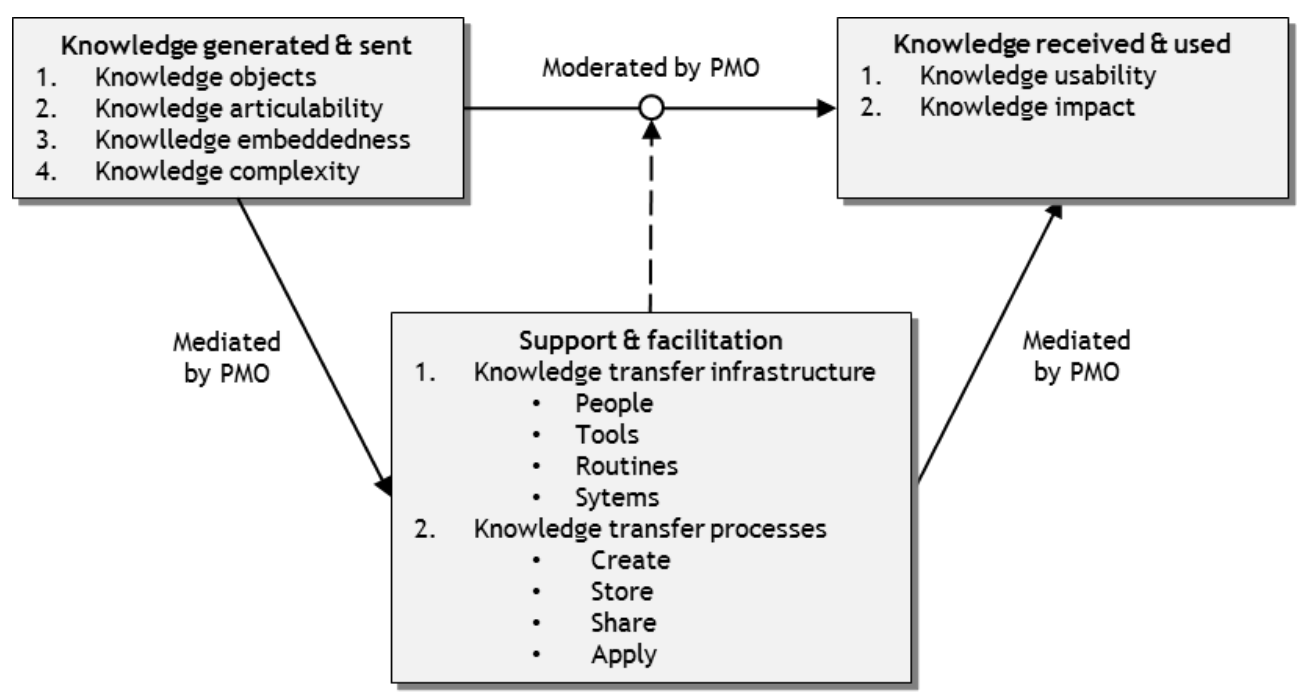

Figure 2: Independent and dependent variables and support and facilitation by the PMO

\subsection{Demographic and contextual information}

One of the common misconceptions about projects is that they are all the same, and that the same or similar tools can be used for all project activities [27]. Managing projects using this approach often leads to failure and/or disappointment, since projects are unique and thus vary in many ways [28]. It is important, therefore, to adopt a framework for categorising projects that addresses the case of projects that are temporary, that are part of an organisation and its culture, and that perform new tasks that have not been done before [28]. Characteristics of projects form an integral part of the demographic information in this research. To address differences among projects, we adopt Shenhar and Dvir's [29] 'diamond' approach, which categorises projects according to four characteristics: novelty, technology, complexity, and pace. Although this is a broad classification, it is very important because it helps to differentiate projects, and specifies a set of rules and behaviours for each project type. Each dimension affects knowledge transfer in its own way [29]. Therefore, the investigation will consider the characteristics of projects to ensure that data collected from the same project types can be compared to avoid distorting the results. The demographics questionnaire will be based on this diamond model to ensure that the respondents choose the answer that best describes the project to which they are referring.

\section{KNOWLEDGE GENERATED AND SENT}

\subsection{Characteristics of knowledge generated and sent}

Four characteristics of knowledge generated and sent (knowledge objects, knowledge articulability/tacitness or explicitness of knowledge, knowledge embeddedness, and knowledge complexity) have been identified.

\subsubsection{Knowledge objects}

Although Sokhanvar, Matthews and Yarlagadda [30] identified eight knowledge objects (project management, technical, procedural, costing, clients, legal and statutory, suppliers, and people), there are three main types of knowledge aspect: project management, technological, and entrepreneurial knowledge [7], [31], [32]. A case study conducted by Wei and Miraglia [32] indicates that new construction techniques (technological knowledge) and innovative project management methodologies (project management knowledge) represent the most important types of knowledge transferred and re-used from project to project in a Chinese construction firm. Due to the unique nature of projects [5], [6], particularly exploratory ones, there is usually a high degree of uncertainty and ambiguity about what knowledge to transfer [4]. Therefore, multiple types of knowledge are needed if improvements to organisational products and services are to be realised [33]. Ultimately, knowledge objects have a direct impact on the impact and usability of knowledge [7], [32]. 


\subsubsection{Knowledge articulability or tacitness/explicitness}

Knowledge articulability is the extent to which knowledge can be verbalised, put into perspective, and/or written [4]. It deals with the tacitness and explicitness of knowledge [34]. Tacit knowledge, which is unspoken and embedded in people's experience, know-how and instinct [34], and is hard to teach and learn, is usually hard to articulate and hard to transfer. On the other hand, explicit knowledge is systematic and formal, expressed, can be formulated in sentences, has a universal character, and can be transferred through standardised procedures, and is therefore easy to articulate and transfer [34]-[38]. Organisations need to know the articulability of the knowledge they are dealing with before attempting to explore and exploit it, since different kinds of knowledge require different methodologies, techniques, mediums, and processes. The most difficult exercise faced by most organisations is to convert tacit knowledge into explicit knowledge, so that it can be stored and used in other projects and to gain competitive advantage over other competitors [33], [39]-[42]. Articulated knowledge is easily captured, stored, and shared with other recipients, as it is pragmatic and easily comprehended [34]. This notion proves that articulable knowledge can be more easily transferred than poorly articulated knowledge [4]. Moreover, less articulated knowledge is difficult to diffuse among an organisation's employees; and this hinders knowledge usability and success in knowledge transfer. However, both tacit and explicit knowledge are crucial in the creation and re-use of knowledge, and contribute positively to projects' success [35].

\subsubsection{Knowledge embeddedness}

Cummings and Teng [4] defined 'embeddedness' as a characteristic of knowledge that deals with the quality of being firmly and deeply entrenched, or fixed in place. According to Argote and Ingram [1] and Cummings and Teng [4], knowledge can be entrenched in individuals, processes, and tools or products, as well as in various sub-networks [34]. Knowledge embeddedness pre-exists and shapes the sharing of relationships between projects [43]. Hsiao, Tsai, Lee, Dun-hou and Lee [44] identified social aspects [45], technical aspects, and innovation as contexts in which knowledge can be embedded. The challenge to be tackled by project organisations is knowing the number of knowledge elements and the related sub-networks that need to be transferred, absorbed, tailored, and adopted by the receiver [4]. Knowledge embedded in people can sometimes be better transferred by transferring the individuals concerned, while knowledge embedded in tools is more readily transferred between units; and the success of knowledge embedded in organisational routines is determined by the transferability of meaning and value [4]. The survey results of Higuchi and Yamanaka [46] indicate that the key factor for effective tacit knowledge-sharing and long-term cocreation is basically related to embeddedness. The more embedded the knowledge, the more difficult it is to transfer; thus knowledge transfer success increases as knowledge embeddedness decreases [4].

\subsubsection{Knowledge complexity}

Knowledge complexity is a characteristic of knowledge that derives from the fact that either a large number of actors and activities are involved in a knowledge process, or neither inputs nor outputs of knowledge processes can be observed [47]. Knowledge complexity (the state of being intricate or convoluted) increases the complicatedness (not easy to unravel or solve) of knowledge transfer; creates unnecessary regular face-to-face interaction; and makes the sharing of knowledge between source and recipient difficult [48]. Thus knowledge complexity negatively affects the successful transfer of knowledge. The less complex the knowledge, the more successful the knowledge transfer. High levels of knowledge complexity lead to a low usability of knowledge by other projects or recipients [49].

\section{KNOWLEDGE RECEIVED AND USED}

\subsection{Characteristics of knowledge received and used}

The characteristics of knowledge received and used - knowledge usability and knowledge impact determine whether the transferred knowledge is functional and practical, and whether it influences projects and their success. The characteristics of knowledge received are directly influenced by the characteristics of knowledge generated and sent [4], [7].

\subsubsection{Extent of use of knowledge (knowledge usability)}

Although it is widely accepted that projects are unique, temporary structures [5], [21], [30], [42], [50], [51] that provide little scope for routinised learning, Brady and Davies [52] argue that similar 
categories of projects produce repeatable and predictable patterns of activities that can be transferred and used by current and future projects. Therefore, the usability of knowledge is largely dependent on the characteristics of knowledge generated and sent. Expected use (received and under consideration), conceptual use (know about it), instrumental use (apply it), and strategic use (teach, share, and improve own understanding) are the dimensions for knowledge use established by Van Waveren, Oerlemans and Pretorious [7]. When considering the usability of knowledge, one should relate it to the characteristics of knowledge generated and sent. The less complex, embedded, and tacit the knowledge, the greater the extent of knowledge use.

\subsubsection{Impact of knowledge}

Meadow and Yuan [7] outlined three kinds of knowledge impact: individual status level impact, individual usage level impact, and group level impact. However, for the impact of knowledge to be measurable, there needs to be a set of variables that have to be defined and benchmarked against the effects of knowledge received and used [7]. It is thus recommended that these variables be aligned with project and organisational goals. Shenhar, Dvir, Levy and Maltz [9] proposed five dimensions of knowledge impact: project efficiency (meeting time, cost, project specifications), benefit to the customer (customer satisfaction and meeting functional performance), impact on the team (satisfaction, retention, and personal growth), business success (commercial value, profits, and revenue), and preparing for the future (sustainability and growth). Reich, Gemino and Sauer [53] identified two main categories of knowledge impact: project management performance, and project performance. There is a direct link between the impact of transferred knowledge and the characteristics of knowledge generated and sent. The less complex, embedded, and tacit, and the more articulate the knowledge, the greater its impact.

\subsection{Influence of knowledge generated and sent on knowledge received and used}

As already alluded to, there is a direct relationship between characteristics of knowledge generated and sent and knowledge received and used, even in organisations without a PMO. The identified characteristics of knowledge generated and sent (type of knowledge, articulability or tacitness/explicitness of knowledge, knowledge embeddedness and complexity) have a direct influence on the extent of use and impact of use of knowledge transferred. However, since this research focuses mainly on the role of PMOs, this relationship falls outside the scope of the investigation, and so will not be explored.

\section{$5 \quad$ KNOWLEDGE TRANSFER SUPPORT AND FACILITATION BY PMO}

\subsection{Knowledge transfer support and facilitation characteristics}

Effective knowledge transfer management increases project performance [3], and PMOs play a supporting (moderating) and facilitating (mediating) role in the transfer of knowledge between projects [5], [11], [54]. These roles are largely dependent on two main variables: the available knowledge transfer infrastructure, and the knowledge transfer processes [25], [31], [49], [55]. Argote and Ingram [1] and Cummings and Teng [4] argue that knowledge is embedded in people, tools, routines and systems; therefore, knowledge transfer success depends on the effective management of the infrastructure and processes of knowledge transfer. Table 1 details the PMO's role in the interaction of knowledge transfer infrastructure and processes in order for organisations to realise improved knowledge transfer between projects. It summarises what the PMO does to each knowledge transfer infrastructure to improve the respective knowledge transfer process. For example, the PMO rolls out appropriate and/or relevant information and communication technologies that support the creation and/or sourcing of knowledge. This results in improved characteristics of the knowledge generated and sent. These two knowledge transfer elements are interdependent; therefore, a balance between them has to be found if the effective and efficient transfer of knowledge between projects is to take place. 
Table 1: Interaction of knowledge transfer infrastructure and processes

\begin{tabular}{|c|c|c|c|c|c|}
\hline & \multicolumn{4}{|c|}{ Knowledge transfer processes } \\
\hline & & Create/Source & Store/Secure & $\begin{array}{l}\text { Share/Disseminate/ } \\
\text { Align }\end{array}$ & Apply/Use \\
\hline \multirow{3}{*}{ 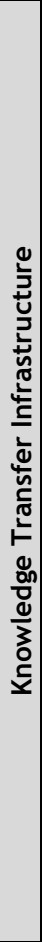 } & $\begin{array}{c}\text { Systems and } \\
\text { tools } \\
\text { (information } \\
\text { and } \\
\text { communication } \\
\text { technology } \\
\text { [ICT]) }\end{array}$ & $\begin{array}{l}\text { Roll out } \\
\text { appropriate } \\
\text { technology } \\
\text { that supports } \\
\text { creation of } \\
\text { knowledge }\end{array}$ & $\begin{array}{l}\text { Provide } \\
\text { systematic, } \\
\text { safe, user- } \\
\text { friendly, and } \\
\text { continuous } \\
\text { access to } \\
\text { knowledge } \\
\text { repositories }\end{array}$ & $\begin{array}{l}\text { Provide } \\
\text { technologically } \\
\text { appropriate } \\
\text { platforms and } \\
\text { mediums for the } \\
\text { effective sharing } \\
\text { and dissemination } \\
\text { of knowledge }\end{array}$ & $\begin{array}{l}\text { Ensure that the } \\
\text { right systems } \\
\text { and tools are in } \\
\text { place to } \\
\text { facilitate } \\
\text { effective } \\
\text { application/use } \\
\text { of knowledge }\end{array}$ \\
\hline & $\begin{array}{c}\text { People } \\
\text { (management \& } \\
\text { employees) }\end{array}$ & $\begin{array}{l}\text { Involve and } \\
\text { motivate } \\
\text { people, as they } \\
\text { are the main } \\
\text { drivers of } \\
\text { knowledge } \\
\text { creation } \\
\text { through } \\
\text { innovation, } \\
\text { lessons learnt, } \\
\text { R\&D programs, } \\
\text { etc. }\end{array}$ & $\begin{array}{l}\text { Encourage } \\
\text { rigorous } \\
\text { application of } \\
\text { project } \\
\text { management } \\
\text { methodology } \\
\text { to serve as } \\
\text { storage of } \\
\text { knowledge }\end{array}$ & $\begin{array}{l}\text { Organise phase } \\
\text { project review } \\
\text { meetings, lessons } \\
\text { learnt, conferences, } \\
\text { expert networks, } \\
\text { seminars, and other } \\
\text { knowledge } \\
\text { dissemination } \\
\text { initiatives driven by } \\
\text { people }\end{array}$ & $\begin{array}{l}\text { Strategically } \\
\text { position people } \\
\text { to drive the } \\
\text { knowledge } \\
\text { use/application } \\
\text { initiative for } \\
\text { realisation of } \\
\text { maximum } \\
\text { benefit }\end{array}$ \\
\hline & $\begin{array}{l}\text { Routines and } \\
\text { processes } \\
\text { (organisational } \\
\text { culture and } \\
\text { structure) }\end{array}$ & $\begin{array}{l}\text { Instil and } \\
\text { encourage } \\
\text { organisational } \\
\text { culture and } \\
\text { structure that } \\
\text { supports } \\
\text { knowledge } \\
\text { creation }\end{array}$ & $\begin{array}{l}\text { Create } \\
\text { routines and } \\
\text { processes that } \\
\text { make the } \\
\text { storage of } \\
\text { knowledge } \\
\text { easy and } \\
\text { effective }\end{array}$ & $\begin{array}{l}\text { Create } \\
\text { organisational } \\
\text { culture and } \\
\text { structure that } \\
\text { encourage } \\
\text { collaboration and } \\
\text { trust to facilitate } \\
\text { effective knowledge } \\
\text { dissemination }\end{array}$ & $\begin{array}{l}\text { Facilitate and } \\
\text { support an } \\
\text { organisational } \\
\text { culture and } \\
\text { structure that } \\
\text { encourage } \\
\text { effective use of } \\
\text { knowledge }\end{array}$ \\
\hline
\end{tabular}

\subsubsection{Knowledge transfer infrastructure}

Gold, Malhotra and Segars [56] define 'knowledge transfer infrastructure' as the technical, structural, and cultural factors that enable the maximisation of social capital for knowledge transfer. It consists of information and communication technology (ICT), organisational culture and structure, and management and employees' support [2], [35], [57]. Since knowledge transfer infrastructure is the backbone and fundamental enabler of effective knowledge transfer processes, PMOs manage knowledge transfer infrastructure very closely [18] for the overall success of knowledge transfer between projects. The success of various knowledge transfer mechanisms social networking, formal training programmes, templates and checklists, intranet and shared network drives [50], project and phase reviews [23], a knowledge repository, expert consultants, brainstorming and mentoring programmes [3], [5] - is largely dependent on efficient knowledge transfer infrastructure. The more effective and efficient the knowledge transfer infrastructure, the stronger the capability of knowledge transfer mechanisms and processes [25]. PMOs assist in selecting the appropriate transfer mechanisms for the successful dissemination of project knowledge [58].

\subsubsection{Systems and tools (ICT)}

What technologies, techniques, and transfer mechanisms would be employed to facilitate smooth, sound and effective knowledge transfer processes? ICT is a critical factor and enabler in knowledge creation and transfer [56], [59] and comprises an element of the structural dimension [60], [61] that is needed to mobilise social capital for the creation of new knowledge through the integration of information and communication systems in an organisation [56]. ICT can support all forms of knowledge transfer [62]; and so a highly developed ICT infrastructure is essential for successful knowledge transfer [42]. Business intelligence, collaboration and distributed learning, knowledge discovery and mapping, opportunity generation, and security were identified by Gold et al. [56] as technological dimensions that are core to effective knowledge transfer. ICT supports knowledge transfer processes and contributes to improved organisational learning and performance by facilitating knowledge transfer processes. Thus ICT positively affects knowledge transfer process 
capabilities [25], and PMOs play a major role in managing ICT to ensure that effective transfer mechanisms are put in place and are used to influence the characteristics of both knowledge generated and knowledge used.

\subsubsection{Routines and processes}

Organisational culture and structure form an important part of the routines and processes of PBOs. Organisational culture consists of collaboration, trust, and a learning culture [42], [63], [64]. Culture shapes assumptions about what knowledge is worth exchanging; defines the relationships between individual and organisational knowledge; and creates the context for the social interaction that determines how knowledge will be shared. It also shapes the processes by which new knowledge is created, legitimated, and distributed in an organisation [62]. Collaboration, trust, and a learning culture positively affect knowledge transfer process capabilities [25]. Better collaboration increases trust, and both lead to improved project performance [65]. 'Organisational structure' refers to the degree to which decision-making authority is shared in an organisation [25]. Decentralised structures facilitate knowledge sharing and collaboration [56], while high centralisation prevents interaction and frequency of communication, and reduces creativity, innovation, and the need to share ideas among individuals [64]. Therefore, decentralised organisational structures are more likely to support knowledge transfer processes than are centralised organisational structures [25]. Thus PMOs closely manage these important, yet tricky, knowledge transfer enablers to facilitate and support successful knowledge transfer.

\subsubsection{People}

People are the principal drivers of knowledge transfer [59], in that they facilitate and coordinate the integration of diverse knowledge assets and combine theoretical and practical knowledge for effective knowledge transfer. 'People' includes management and employees; and their buy-in and support of knowledge transfer is vital for successful knowledge transfer across projects. Successful knowledge transfer is mainly linked to people, because learning and sharing knowledge are social activities that take place between the organisation's greatest asset - its people [64]. Support and backing from top management is crucial not only for knowledge transfer success, but also for overall project success. Top management has to create a highly conducive and supportive atmosphere in which to advance project knowledge transfer effectiveness and success [42]. The support of top management positively affects knowledge transfer process capabilities [25], and PMOs play a highly significant role in managing this knowledge transfer enabler.

\subsubsection{Knowledge transfer processes}

Knowledge transfer processes support and facilitate the effective and efficient transfer of knowledge between projects. The processes consist of knowledge creation and sourcing, compilation and transformation/alignment, dissemination/distribution/sharing, application and value realisation, and ensuring its availability to future users [31], [66]. Knowledge capture and transfer is also recognised by the Project Managment Institute [5]. Knowledge transfer processes are interlinked; for example, the creation of organisational knowledge requires the sharing, integration, and dissemination of knowledge [56]. PMOs are regarded as a source of centralised integration and as a repository of knowledge that can be used to inform more effective and efficient project management [61]. They also play a significant role in the management of knowledge transfer processes.

\subsubsection{Knowledge creation and sourcing}

Knowledge creation can be interpreted as an interlinked and boundary-crossing process of knowledge sharing, knowledge integration, and knowledge generation [42]. It can include the development of new information and knowledge from raw data, but it also recombines and reorganises existing knowledge without necessarily creating completely new knowledge [48]. The uniqueness and temporariness of projects presents a huge opportunity to acquire new knowledge for individuals and for the organisation [50]. Technical specialists, innovators, R\&D programs, lessons learnt programmes, and external sources are some of the knowledge sources identified by the Knowledge Research Institute [66]. In order to stay ahead of their competitors, organisations need continuously to innovate and develop or acquire knowledge that is difficult for competitors to copy [35], [39]. Nonaka [67] developed a framework of knowledge creation mechanisms that is based on tacit and explicit knowledge, and created four groups: socialisation (tacit to tacit), internalisation (explicit to tacit), externalisation (tacit to explicit), and combination (explicit to explicit). Strategic alliances are also a good example of creating knowledge through organisational learning of the alliances [68]. PMOs influence the knowledge creation and sourcing process, having identified the 
characteristics of the required knowledge; and this makes the knowledge transfer process significantly effective as the appropriate knowledge is generated and transferred.

\subsubsection{Knowledge storage and securing/protection}

The main objective of storing knowledge is to provide systematic and continuous access to the organisation's knowledge repositories [30]. A rigorous application of project management methodology makes the storage of knowledge habitual [63]. Documenting decisions and assumptions about resources, time, quality requirements, costs, etc., is a way to store and share knowledge [50]. Organisations store knowledge in the form of both tacit or explicit knowledge; and PMO leaders can overcome the challenges of storing knowledge by adopting the strategy of integrating knowledge use into the IT systems that support processes among knowledgeable workers. Knowledge protection is one of the important processes driven by PMOs that help organisations to keep and enjoy the competitive advantage that comes about as a result of their successful knowledge transfer processes. The processes are security- and compliance-oriented, and are designed to protect and safeguard knowledge from illegal or inappropriate use (even theft) by internal or external stakeholders [56]. Therefore, it would be pointless for organisations to innovate and create new and unique knowledge, yet fail to protect this knowledge, as competitors will pounce, and organisations may find themselves being victims of the failure to protect their knowledge.

\subsubsection{Knowledge sharing/dissemination and alignment}

Knowledge is only valuable if it is appropriate, accurate, accessible, and shared through appropriate mechanisms [62]. Therefore, effective knowledge transfer requires efficient systems, methods, protocols, and procedures. The challenge of knowledge transfer in the project environment is to capture the lessons learned (both positive and negative) on one project and to share them with other projects in order to increase efficiency and competitiveness [69]. Periodic closeout meetings (at the end of each project phase) and after-action reviews (immediately after an important event) are valuable for interrogating, learning, sharing, and disseminating knowledge to the project team and to the PMO [23]. Risks associated with new projects are reduced by the methodical remembering and documenting of project experiences [63]. There is a growing need in organisations effectively to put into practice knowledge transfer systems with the aim of going beyond limits for the purpose of disseminating vital knowledge throughout projects, teams, and organisations [70], and PMOs help to fulfil this need. Expert networks, educators/trainers, seminars, and conferences are some of the knowledge dissemination initiatives put in place by PMOs [66]. However, PMOs should guard against knowledge overload, and focus on disseminating knowledge that will add value to the projects and the organisation by incorporating knowledge into the project work-flow, process, template, and/or specification [71]. Knowledge alignment is one of the most important aspects of knowledge transfer: it deals with bringing the captured data into line so that it is used to the benefit of the recipient, appropriately, efficiently, and at the right place and time, since gathering, evaluating, classifying, and structuring information will not automatically result in successful knowledge transfer. PMOs help to align and use the correct knowledge in the right situations to enable the full value of the knowledge to be realised [56].

\subsubsection{Knowledge application/use}

Application, re-use, exploitation, capitalisation, and use of knowledge [24] involve making use of the acquired and stored knowledge. Surprisingly, very little has been documented or said about the outcomes of effective knowledge application and its implications and/or its contribution to knowledge transfer [56]. PMO leaders and project managers help to align knowledge strategies and tactics with the enterprise's direction, facilitate and monitor knowledge transfer-related activities and programmes, and establish cross-functional teams and collaboration efforts [49].

\subsection{Moderating influence of the PMO on the relationship between knowledge generated and sent and knowledge received and used}

From the above narrative, it is clear that PMOs moderate (support) the relationship between knowledge generated and sent and knowledge received and used. They put knowledge transfer infrastructure and knowledge transfer processes in place that ensure that the appropriate knowledge is generated, stored, aligned, protected, transferred, received, and used by the receiving project; hence the first proposition:

Proposition 1: The PMO moderates the relationship between knowledge sent and knowledge received (flow of knowledge between projects). 
Even without the existence of a PMO, there is a relationship between knowledge generated and sent and knowledge received and used. This relationship will not be explored further, as it falls outside the scope of the investigation.

\subsection{Direct influence of characteristics of knowledge generated and sent on the PMO's mediation role}

Projects produce various knowledge characteristics. Not all knowledge produced by projects is useful or relevant [72]. The characteristics of knowledge generated and sent influence the PMO's mediating (facilitation) role in the transfer of knowledge across projects. The PMO's mediation function is determined, therefore, by the characteristics of the knowledge generated. For example, the PMO decodes less articulate and complicated knowledge to improve its transferability to other projects. PMOs may also decide to transfer an individual who holds the tacit knowledge [38], depending on the efforts required to decode the tacit knowledge in comparison with the time it would take to decode the tacit and complicated knowledge, and the costs involved. PMOs decide on the knowledge transfer mechanisms to be used to transfer knowledge effectively, based on the characteristics of the knowledge generated. Tacit knowledge require people, while explicit knowledge is best transferred through tools and systems [62], [70]. The above narrative supports the second proposition:

Proposition 2: The characteristics of knowledge generated and sent (knowledge objects, articulability or tacitness/explicitness of knowledge, knowledge embeddedness and complexity) influence the PMO's mediation (facilitation) role.

\subsection{Direct influence of PMO's mediation role on knowledge received and used}

The realisation of the desired characteristics of knowledge leads to improved knowledge transfer between projects [24]. The absorptive capacity of an organisation is key to ensuring knowledge transfer [73]. To avoid flooding receiving projects with huge volumes of knowledge that may not necessarily be useful to them, PMOs determine the characteristics of the knowledge received and used by ensuring that the appropriate knowledge is transmitted, and that this happens via appropriate mediums. They also help to develop the absorptive capabilities of the receiving projects, to ensure that the received knowledge is absorbed and used to full effect [52]. PMOs need to have the absorptive capacity to receive knowledge from the project(s) [71] in order to improve the quality and effectiveness of the knowledge received and used. In some instances, rather than transferring knowledge in explicit form, PMOs recommend the transfer of individuals who have the requisite knowledge [70] to the needy project. PMOs also conduct lessons learnt workshops to boost their knowledge repository and use documented project experiences in future projects. This leads to proposition 3 .

Proposition 3: The PMO's mediation role improves the use and impact of knowledge received.

To help answer the research question, a conceptual model is presented in Figure 3, and three propositions are put forward. The model suggests that the PMO moderates and mediates the transfer of knowledge between projects. 


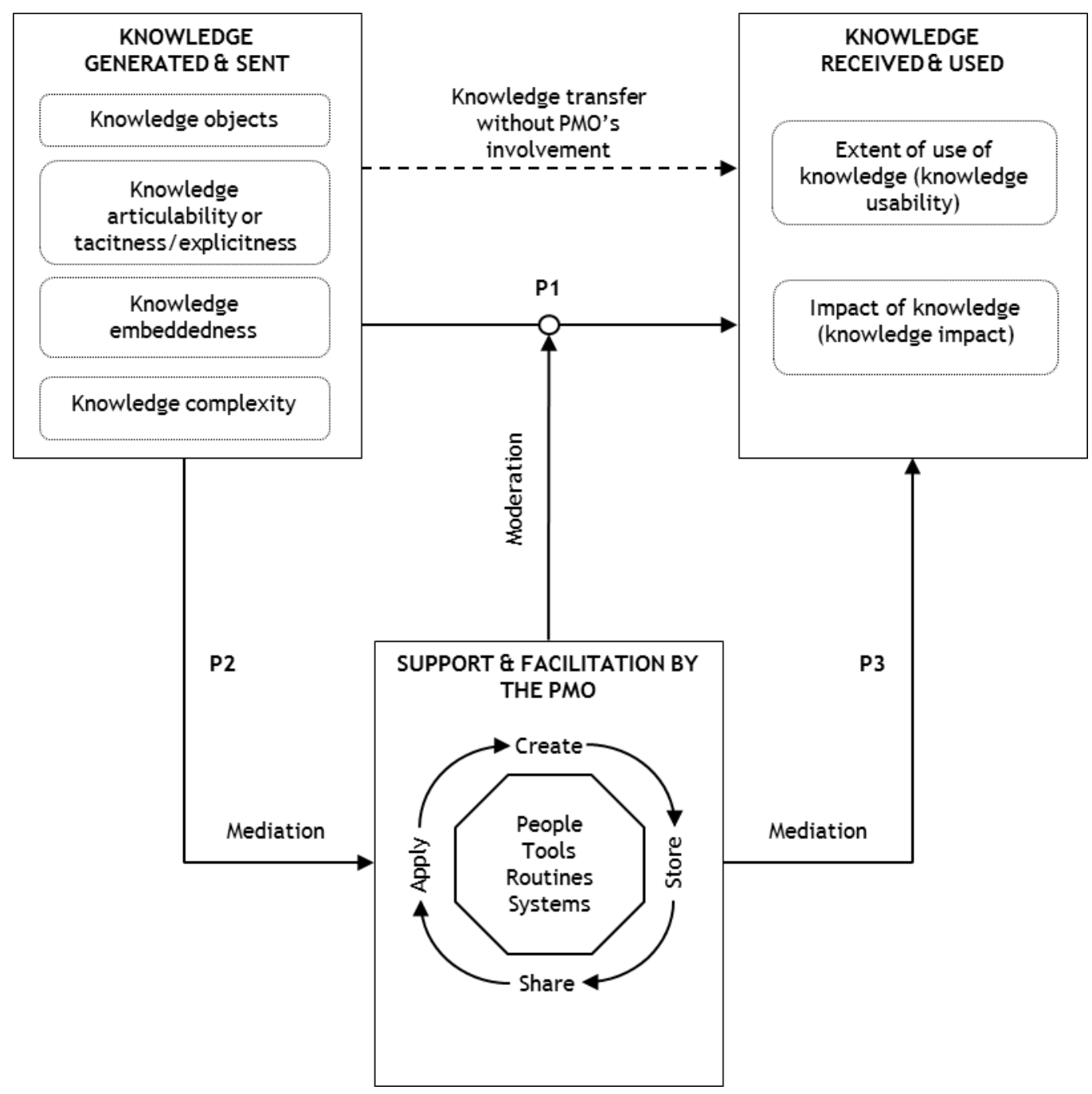

Figure 3: Conceptual model

\section{CONCLUSION AND DISCUSSION}

Based on a literature survey, this paper has explored and presented a conceptual model of the role played by PMOs in the transfer of knowledge between projects, and has argued that, without a PMO, this role cannot be effectively and efficiently fulfilled. The model suggests that the PMO moderates and mediates the transfer of knowledge between projects. An overview of the characteristics of the knowledge generated and sent, the characteristics of the knowledge received and used, and the direct relationship between the two - as well as the influence of the PMO - has been presented. The paper has put forward three main propositions:

Proposition 1: $\quad$ The PMO moderates the relationship between knowledge sent and knowledge received (flow of knowledge between projects).

Proposition 2: The characteristics of knowledge generated and sent (knowledge objects, articulability or tacitness/explicitness of knowledge, knowledge embeddedness and complexity) influence the PMO's mediation (facilitation) role.

Proposition 3: The PMO's mediation role improves the use and impact of knowledge received. 
These propositions will be further investigated and empirically tested in a number of PMOs as part of subsequent research studies.

This study has certain implications for the research into the practice of PMOs. The conceptual model seeks to close the gap between the short- and long-term objectives of projects in a project environment where most project team members focus on the short-term goals of the project, and often fail to see capturing and transferring project knowledge across projects as a priority, or as important for long-term benefits to the organisation [7]. The PMO creates a strong link between the characteristics of the knowledge generated and sent and the characteristics of the knowledge received and used, and ensures that the two are interlinked for maximum benefits and efficiency. No literature could be found on the role of PMOs in the transfer of knowledge between projects; hence the conclusion that there is a gap in the literature. For the practitioner involved in a PMO, this paper presents a framework of factors about knowledge transfer to consider. The planned empirical work should contribute further to the practice of PMOs.

The study has certain limitations. It does not compare the impact of knowledge transfer between PBOs with and without a PMO, but rather focuses on the role of PMOs in the transfer of knowledge across projects. The framework is only applicable to PBOs, and so should not be blindly applied to any organisation. For future studies, therefore, it is important to modify the model so that it can be applied to organisations in general.

\section{ACKNOWLEDGEMENTS}

The authors gratefully acknowledge the valuable guidance and contributions of Professor Leon Oerlemans of the Department of Organization Studies, Tilburg University in the Netherlands.

\section{REFERENCES}

[1] Argote, L. and Ingram, P. 2000. Knowledge transfer: A basis for competitive advantage in firms. Organizational Behavior and Human Decision Processes, vol. 82, no. 1, pp. 150-169.

[2] Hanisch, B., Lindner, F., Mueller, A. and Wald, A . 2009. Knowledge management in project environments. Journal of Knowledge Management, vol. 13, no. 4, pp. 148-160.

[3] Louw, I.R., Steyn, H. and van Waveren, C.C. 2017. Inhibitors to the transfer of knowledge generated on projects: A case study within a construction company. Journal of Contemporary Management, vol. 14, pp. 986-1010.

[4] Cummings, J.L. and Teng, B. 2003. Transferring R \& D knowledge: The key factors affecting knowledge transfer success. Journal of Engineering Technology Management, vol. 20, pp. 39-68.

[5] Project Managment Institute. 2017. A guide to the Project Management Body of Knowledge PMBOK Guide, 6th ed. Project Mangement Institute, Inc., Pennsylvania, USA

[6] Aubry, M. and Hobbs, B. 2010. A fresh look at the contribution of project management to organizational performance. Project Management Journal, vol. 42, no. 1, pp. 3-16.

[7] Van Waveren, C.C., Oerlemans, L.A.G. and Pretorius, M.W. 2014. Knowledge transfer in project-based organizations: A conceptual model for investigating knowledge type, transfer mechanism and transfer success. IEEE Transactions on Engineering Management, pp. 1176-1181.

[8] Unger, B.N., Gemuinden, H.G. and Aubry, M. 2012 The three roles of a project portfolio management office: Their impact on portfolio management execution and success. International Journal of Project Management, vol. 30, no. 5, pp. 608-620.

[9] Shenhar, A.J., Dvir, D., Levy, O. and Maltz, A.C. 2001. Project success: A multidimensional strategic concept. Long Range Planning, vol. 34, no. 6, pp. 699-725.

[10] Artto, K., Kulvik, I., J. Poskela, I. and Turkulainen, V. 2011. The integrative role of the project management office in the front end of innovation. International Journal of Project Management, vol. 29, no. 4, pp. 408-421.

[11] Julian, J. 2008. How project management office leaders facilitate cross-project learning and continuous improvement. Project Management Journal, vol. 39, no. 3, pp. 43-58.

[12] Fong, P.S.W. and Kwok, C.W.C. 2009. Organizational culture and knowledge management success at project and organizational levels in contracting firms. Journal of Construction Engineering and Management, vol. 135, no. 12, pp. 1348-1357.

[13] Kerzner, H. 2006. Project management best practices: Achieving global excellence. Hoboken, NJ: John Wiley \& Sons.

[14] Aubry, M., Hobbs, B., Muller, R. and Blomquist, T. 2010. Identifying forces driving PMO changes. Project Management Journal, vol. 41, no. 4, pp. 30-45.

[15] Pellegrinelli, S. and Garagna, L. 2009. Towards a conceptualisation of PMOs as agents and subjects of change and renewal. International Journal of Project Management, vol. 27, no. 7, pp. 649-656. 
[16] Hobbs, B. and Aubry, M. 2008. An empirically grounded search for a typology of project management offices. Project Management Journal, vol. 39, pp. 569-582.

[17] Pinto, A., De Matheus Cota, M.F. and Levin, D.G. 2010. The PMO maturity cube: A project management office maturity model. PMI Research and Education Congress 2010, Washington, DC, pp. 1-43.

[18] Hill, G.M. 2004. Evolving the project management office: A competency continuum. Information Systems Managemen, vol. 21, no. 4, pp. 45-51t.

[19] Kwak, Y. and Dai, C. 2000. Assessing the value of project management offices (PMO), in PMI Research Conference, Draft conference paper, pp.1-8.

[20] Rad, P.F. 2001. Is your organization a candidate for project management office PMO? AACE International Transactions, vol. 7, no. 1, pp. 1-4.

[21] Jerry, J. 2008. How project management office leaders facilitate cross-project learning and continuous improvement. Project Management Journal, vol. 39, no. 3, pp. 43-58.

[22] Bates, W.S. 1998. Improving project management: Better project management begins with a project management office. IIE Solutions, vol. 30, no. 10, pp. 42-48.

[23] Nicholas, J. and Steyn, H. 2017. Project management for engineering, business and technology, 5th ed. Routledge, London.

[24] Heisig, P. 2009. Harmonisation of knowledge management - Comparing $160 \mathrm{KM}$ frameworks around the globe. Journal of Knowledge Management, vol. 13, no. 4, pp. 4-31.

[25] Lee, S., Gon Kim, B. and Kim, H. 2012. An integrated view of knowledge management for performance. Journal of Knowledge Management, vol. 16, no. 2, pp. 183-203.

[26] Jafari, N. and Charband, Y. 2016. Knowledge sharing mechanisms and techniques in project teams: Literature review, classification, and current trends. Computers in Human Behavior, vol. 62, pp. 730-742.

[27] Frank, M., Sadeh, A. and Ashkenasi, S. 2011. The relationship among systems engineers' capacity for engineering systems thinking, project types, and project success. Project Management Journal, vol. 42, no. 5, pp. 31-41.

[28] Dvir, D.O.V., Sadeh, A. and Malach-Pines, A. 2006. Projects and project managers - The relationship between project managers' personality, project types and project success. Project Management Journal, vol. 37, no. 5, pp. 36-49.

[29] Shenhar, A.J. and Dvir, D. 2007. Reinventing project management: The Diamond approach to successful growth. Boston: Harvard Business School Press.

[30] Sokhanvar, S., Matthews, J. and Yarlagadda, P. 2014. Importance of knowledge management processes in a project-based organization: A case study of research enterprise. Procedia Engineering, vol. 97, pp. 1825-1830.

[31] Kasvi, J.J.J., Vartiainen, M. and Hailikari, M. 2003. Managing knowledge and knowledge competences in projects and project organisations. International Journal of Project Management, vol. 21, no. 8, pp. 571582.

[32] Wei, Y. and Miraglia, S. 2017. Organizational culture and knowledge transfer in project-based organizations: Theoretical insights from a Chinese construction firm. International Journal of Project Management, vol. 35, no. 4, pp. 571-585.

[33] Kaewchur, O., Anussornnitisarn, P. and Pastuszak, Z. 2009. The mediating role of knowledge sharing on information technology and innovation. International Journal of Management, Knowledge and Learning, vol. 2, no. 2, pp. 227-242.

[34] Fernie, S., Green, S.D., Weller, S.J. and Newcombe, R. 2003. Knowledge sharing: Context, confusion and controversy. International Journal of Project Management, vol. 21, pp. 177-187.

[35] Owen, J., Burstein, F. and Mitchell, S. 2004. Knowledge reuse and transfer in a project management environment. Journal of Information Technology Case and Application Research, vol. 6, no. 4, pp. 21-35.

[36] Kulkarni, U.R., Ravindran, S. and Freeze, R. 2007. A knowledge management success model : Theoretical development and empirical validation. Journal of Management Information Systems, vol. 23, no. 3, pp. 309-347.

[37] Anand, G., Ward, P.T. and Tatikonda, M.V. 2010. Role of explicit and tacit knowledge in Six Sigma projects: An empirical examination of differential project success. Journal of Operations Management, vol. 28, no. 4, pp. 303-315.

[38] Bellini, A., Aarseth, W. and Hosseini, A. 2016. Effective knowledge transfer in successful partnering projects. Energy Procedia, vol. 96, no. 1876, pp. 218-228.

[39] Lubit, R. 2001. Knowledge management: The keys to sustainable competitive advantage. Organizational Dynamics, vol. 29, no. 4, pp. 164-178.

[40] Cavusgil, T., Calantone, R. and Zhao Y. 2003. Tacit knowledge transfer and firm innovation capability. Journal of Business \& Industrial Marketing, vol. 18, no. 16-21.

[41] Chang, K., Lee, S. and Won, I. 2005. KMPI: Measuring knowledge management performance. Information \& Management, vol. 42, pp. 469-482.

[42] Lindner, F. and Wald, A. 2011. Success factors of knowledge management in temporary organizations. International Journal of Project Management, vol. 29, no. 7, pp. 877-888.

[43] Nielsen, B.B. 2005. The role of knowledge embeddedness in the creation of synergies in strategic alliances. Journal of Business Research, vol. 58, pp. 1194-1204.

[44] Hsiao, R., Tsai, S.D., Lee, C., Dun-hou, S. and Lee, C. 2005. The problems of embeddedness: Knowledge transfer, coordination and reuse in information systems. Organization Studies, vol. 27, no. 9, pp. 12891317. 
[45] Sydow, J., Lindkvist, L. and Defillippi, R. 2004. Project-based organizations, embeddedness and repositories of knowledge: Editorial. Organizational Studies, vol. 25, no. 9, pp. 1475-1489.

[46] Higuchi Y. and Yamanaka, Y. 2017. Knowledge sharing between academic researchers and tourism practitioners: A Japanese study of the practical value of embeddedness, trust and co-creation. Journal of Sustainable Tourism, vol. 25, no. 10, pp. 1456-1473.

[47] Floricel, S., Michela, J.L. and Piperca, S. 2016. Complexity, uncertainty-reduction strategies, and project performance. International Journal of Project Management, vol. 34, no. 7, pp. 1360-1383.

[48] Kang, J., Rhee, M. and Kang, K.H. 2010. Revisiting knowledge transfer: Effects of knowledge characteristics on organizational effort for knowledge transfer. Expert Systems with Applications, vol. 37, no. 12, pp. 8155-8160.

[49] Liebowitz, J. and Megbolugbe, I. 2003. A set of frameworks to aid the project manager in conceptualizing and implementing knowledge management initiatives. International Journal of Project Management, vol. 21, no. 3, pp. 189-198.

[50] Terzieva, M. 2014. Project knowledge management: How organizations learn from experience. Procedia Technology, vol. 16, pp. 1086-1095.

[51] Pemsel, S. and Wiewiora, A. 2013. Project management office a knowledge broker in project-based organisations. International Journal of Project Management, vol. 31, no. 1, pp. 31-42.

[52] Brady, T. and Davies, A. 2004. Building project capabilities: From exploratory to exploitative learning. Organization Studies, vol. 25, no. 9, pp. 1601-1621.

[53] Reich, B.H., Gemino, A. and Sauer, C. 2014. How knowledge management impacts performance in projects: An empirical study. International Journal of Project Management, vol. 32, no. 4, pp. 590-602.

[54] Hobbs, B. and Aubry, M. 2007. A multi-phase research program investigating project management offices (PMOs): The results of phase 1. Project Management Journal, vol. 38, no. 1, pp. 74-86.

[55] Durst, S. and Runar, I. 2012. Knowledge management in SMEs: A literature review. Journal of Knowledge Management, vol. 16, no. 6, pp. 879-903.

[56] Gold, A.H., Malhotra, A. and Segars, A.H. 2001. Knowledge management: An organizational capabilities perspective. Journal of Management Information Systems, vol. 18, no. 1, pp. 185-214.

[57] Rowley, J. 1999. What is knowledge management? Library Management, vol. 20, no. 8, no. 8, pp. 416420.

[58] Simonin, B.L. 1999. Ambiguity and the process of knowledge transfer in strategic alliances. Strategic Management Journal, vol. 20, pp. 595-623.

[59] Chourides, P., Longbottom, D. and Murphy, W. 2003. Excellence in knowledge management: An empirical study to identify critical factors and performance measures. Measuring Business Excellence, vol. 7, no. 2, pp. 29-45.

[60] Bresnen, M., Edelman, L., Newell, S., Scarbrough, H. and Swan, J. 2003. Social practices and the management of knowledge in project environments. International Journal of Project Management, vol. 21, pp. 157-166.

[61] Desouza, K.C. and Evaristo, J.R. 2006. Project management offices: A case of knowledge-based archetypes. International Journal of Information Management, vol. 26, no. 5, pp. 414-423.

[62] Karlsen. J.T. and Gottschalk, P. 2004. Factors affecting knowledge transfer in IT projects. Engineering Management Journal, vol. 16, no. 1, pp. 3-11.

[63] Schindler, M. and Eppler, M.J. 2003. Harvesting project knowledge: A review of project learning methods and success factors. International Journal of Project Management, vol. 21, no. 3, pp. 219-228.

[64] Susanty, A., Utami, N. and Yugi, M. 2012. Key success factors that influence knowledge transfer effectiveness: A case study of Garment Sentra at Kabupaten Sragen. Procedia Economics and Finance, vol. 4, pp. 23-32.

[65] Bond-Barnard, T.J., Steyn, H. and Fabris-Rotelli, I. 2013. The impact of a call centre on communication in a programme and its projects. International Journal of Project Management, vol. 31, no. 7, pp. 10061016.

[66] Knowledge Research Institute. 2000. Knowledge transfer processes. Knowledge Research Institute, Inc., pp. 1-102.

[67] Nonaka, I. 1994. A dynamic theory of organizational knowledge creation. Organization Science, vol. 5, no. 1, pp. 14-37.

[68] Mowery, D.C., Oxley, J.E. and Silverman, B.S. 1996. Strategic alliances and interfirm knowledge transfer. Strategic Management Journal, vol. 17, pp. 77-91.

[69] Pretorius, C.J. and Steyn, H. 2005. Knowledge management in project environments. South African Journal of Business Management, vol. 36, no. 3, pp. 41-50.

[70] Carrillo, P.M., Robinson, H.S., Anumba, C.J. and Bouchlaghem, N.M. 2006. A knowledge transfer framework: The PFI context. Construction Management and Economics, vol. 24, no. October, pp. 10451056.

[71] Bell, L., van Waveren, C.C. and Steyn, H. 2016. Knowledge-sharing within the project-based organizsation: A knowledge-pull framework. South African Journal of Industrial Engineering, vol. 27, no. 4, pp. 18-33.

[72] McClory, S., Read, M. and Labib, A. 2017. Conceptualising the lessons-learned process in project management: Towards a triple-loop learning framework. International Journal of Project Management vol. 35, no. 7, pp. $1322-1335$.

[73] Szulanski, G. 2000. The process of knowledge transfer: A diachronic analysis of stickiness. Organizational Behavior and Human Decision Processes, vol. 82, no. 1, pp. 9-27. 